\title{
Comparison of Tenofovir and Entecavir in the Prevention of Hepatocellular Carcinoma Occurrence in Patients with Chronic Hepatitis B
}

\author{
Antonio Facciorusso ${ }^{a}$ Ivan Cincione ${ }^{b}$ Rodolfo Sacco ${ }^{a}$ \\ aDepartment of Medical Sciences, Gastroenterology Unit, Ospedali Riuniti di Foggia, Foggia, Italy; bepartment of \\ Clinical and Experimental Medicine, University of Foggia, Foggia, Italy
}

Dear Editor,

We read with great interest the meta-analysis recently published by Liu et al. [1] in Liver Cancer. Through a meta-analysis of 7 retrospective studies enrolling 35,785 patients, the authors found a $25 \%$ lower risk of hepatocellular carcinoma (HCC) occurrence in patients treated with tenofovir disoproxil fumarate (TDF) as compared to those treated with entecavir (ETV), thus concluding that TDF treatment is associated with significantly fewer cases of HCC when compared to ETV [1].

These findings are in line with another recent metaanalysis published in the field [2]. In this meta-analysis, including 14 studies, on unadjusted analysis the risk of HCC was not statistically different between ETV and TDF (incidence risk ratio 1.28; 95\% confidence interval, 0.99-1.66); however, when utilizing available adjusted data (multivariate or propensity-matched data), the risk of HCC among patients treated with ETV was $27 \%$ higher when compared to TDF, a result similar to the aforementioned meta-analysis by Liu et al. [1]. Of note, the overall confidence in estimates was rated as very low because based only on observational studies and with high heterogeneity.

However, serious concerns should be raised on the literature search adopted in the study by Liu et al. [1] as

karger@karger.com www.karger.com/lic

Karger!

bOPEN ACCESS
C 2021 The Author(s)

Published by S. Karger AG, Basel

This article is licensed under the Creative Commons AttributionNonCommercial-NoDerivatives 4.0 International License (CC BYNC-ND) (http://www.karger.com/Services/OpenAccessLicense). Usage and distribution for commercial purposes as well as any distribution of modified material requires written permission. several other meta-analyses have been recently published in the field with a significantly larger number of included studies. In particular, Tseng et al. [3] published a comprehensive meta-analysis of 31 studies finding no significant difference between TDF and ETV in their association with incident HCC [3]. In this review of 31 studies involving 119,053 patients, the 5-year cumulative incidence of HCC was $5.97 \%$ for ETV and $3.06 \%$ for TDF in studies with unmatched populations $(p<0.0001)$ and $3.44 \%$ for entecavir and $3.39 \%$ for TDF $(p=0.87)$ in propensitymatched studies [3]. Again, analysis of 14 comparative studies with covariate adjustment found that TDF and ETV had similar risk of HCC occurrence (adjusted hazard ratio $0.88,0.73-1.07 ; p=0.20)$ [3].

These findings point out the second limitation to the analysis by Liu et al. [1], namely, the lack of adjustment for several potential confounders such as cirrhosis, age, and other diseases. The aforementioned studies clearly highlight the importance of adjustment when analyzing long-term outcomes in patients with liver cirrhosis as the natural course of the disease can be influenced by several factors, even not strictly related to the underlying chronic viral infection [4].

For instance, the earlier availability of ETV would have biased many studies to select older patients with 
more advanced liver disease who met the treatment criteria before TDF became available [5]. Matched cohorts, which are methodologically more robust, provide stronger evidence and should be adequately considered when performing systematic reviews and meta-analysis, in particular in highly heterogeneous cohorts as in the case of hepatitis B patients. This is particularly important given the scarcity of randomized clinical trial-based evaluations in this field. In fact, to date, there are no large scale trials directly comparing the 2 treatments for the management of chronic hepatitis B infection.

Therefore, we think other studies and large randomized controlled trials are needed to clarify this important issue; meanwhile, definitive assumptions on the superiority of 1 treatment over the other cannot be made.

\section{Conflict of Interest Statement}

The authors have no conflicts of interest to declare.

\section{Funding Sources}

The authors did not receive any funding.

\section{Author Contributions}

Study concept and design: Antonio Facciorusso; acquisition of data: Antonio Facciorusso and Ivan Cincione; drafting of the manuscript: Antonio Facciorusso; critical revision of the manuscript for important intellectual content: Rodolfo Sacco; approval of the final manuscript: all of the authors; guarantor of the article: Antonio Facciorusso.

\section{References}

1 Liu H, Shi Y, Hayden JC, Ryan PM, Rahmani J, Yu G. Tenofovir treatment has lower risk of hepatocellular carcinoma than entecavir treatment in patients with chronic hepatitis B: a systematic review and meta-analysis. Liver Cancer. 2020 Aug;9(4):468-76.

2 Dave S, Park S, Murad MH, Barnard A, Prokop L, Adams LA, et al. Comparative effectiveness of entecavir vs tenofovir for preventing hepatocellular carcinoma in patients with chronic hepatitis B: a systematic review and meta-analysis. Hepatology Forthcoming. 2020 Apr 10.

3 Tseng CH, Hsu YC, Chen TH, Ji F, Chen IS, Tsai YN, et al. Hepatocellular carcinoma inci- dence with tenofovir versus entecavir in chronic hepatitis B: a systematic review and meta-analysis. Lancet Gastroenterol Hepatol. 2020 Dec;5(12):1039-52.

4 Facciorusso A, Garcia Perdomo HA, Muscatiello N, Buccino RV, Wong VW, Singh S. Systematic review with meta-analysis: change in liver stiffness during anti-viral therapy in patients with hepatitis B. Dig Liver Dis. 2018 Aug;50(8):787-94.

5 Abd El, Aziz MA, Sacco R, Facciorusso A. Nucleos(t)ide analogues and hepatitis B virus-related hepatocellular carcinoma: a literature review. Antivir Chem Chemother. 2020 Jan-Dec;28:204020662092133. 